\title{
Energy saving and optimum insulation thicknesses in building upgrading
}

\author{
Mateusz Orzechowski ${ }^{1}$, and Tadeusz Orzechowski ${ }^{2, *}$ \\ ${ }^{1}$ Statistical Office in Kielce, Wróblewskiego 2, 25-369 Kielce,Poland \\ ${ }^{2}$ Kielce University of Technology, Al. Tysiąclecia PP 7, 25-314 Kielce, Poland
}

\begin{abstract}
Heat pumps are classified as ecologically friendly heat-generating devices and are one of the most suitable solutions for improving energy efficiency in buildings. Systems based on such solutions replace conventional sources very well. Household sector is one of the major energy consumers, where energy is used mainly for space heating and providing hot water. To increase renewable energy consumption levels, it is necessary to take decisive actions aimed at energy modernization of existing buildings. Particular emphasis must be put on the use of renewable energy sources. A wide selection of insulation materials is available on the market, however proper technologies are required to apply those materials, especially for historical buildings. Therefore, while planning investment, a question must be answered what type of material should be used, and what costs that will generate. The paper presents simple methodology for calculating the optimal insulation thickness so that the costs of the thermo-modernization would be covered by savings in heating expenses, when bank loan for the project is available at fixed interest rate.
\end{abstract}

\section{Introduction}

In the 21 st century, communities have to face different threats that result from a carefree attitude to the use of natural resources in the last century. To a far extent that refers to over-exploitation of conventional energy sources, which directly leads to the natural environment deterioration. In particular, that refers to large urban agglomerations with dense built-up environment, in which the limit values of air pollutant levels are periodically exceeded. The situation occurs clearly more frequently during the heating period, especially in the areas where heat for buildings is predominantly provided by local facilities. The solutions to the problem involve boiler modernisation and advanced combustion processes [1,2], and also a reduction in energy consumption due to thermal upgrading. The best results are obtained when both methods are combined [3].

Heat pumps are classified as ecologically friendly heat-generating devices and are one of the most suitable solutions for improving energy efficiency in buildings [4]. Heating systems based on such solutions replace conventional schemes, such as electric, coal, gas and oil boilers, etc. for the generation of heat and domestic hot water. As a result, the heat pump market has been growing continually. According to [5], the highest sales of new devices per 1000 households in the years 20072016 were recorded in Norway, Finland and Greece. Poland took the sixteenth place, after the Czech Republic, and in front of Slovakia. The devices are mostly compressor heat pumps, half of which are air-to- water pumps. Other types, e.g. absorption or gas heat pumps are very rarely found.

In Poland, heat is mainly used for space heating purposes, domestic hot water and air conditioning. This represents more than $31 \%$ of total energy consumption. With such a high percentage of energy consumption, a reduction in the share of conventional heat production methods has become a priority for the coming years. Additionally, air-to-water type heat pumps are particularly suitable as a replacement of heating devices in energy upgrading of buildings [6]. They are easy to install and integrate into existing heating systems. External collectors or boreholes are not required [7]. Air is a good source of renewable energy and it is also possible to combine this solution with solar collectors, which offers one of the most effective options [8]. Airsource heat pumps work well enough under severe climatic conditions [9]. However, in order to optimally set their parameters, it is necessary to take into account locally prevailing conditions [10], including the parameters of supply and the heating medium return [11]. The investigations indicate that when selecting a device, it is also necessary to consider the impact of the working medium type on the coefficient of performance $(C O P)[12]$

According to the Energy Market Agency forecasts, ultimate energy consumption in the residential sector should be reduced by $3.8 \%$ in the next 15 years. To achieve those levels, it is necessary to take decisive actions aimed at energy modernization of existing buildings. That requires proper selection of optimal

\footnotetext{
Corresponding author: todek@tu.kielce.pl
} 
solutions, especially in the case of old buildings, which being under supervision of conservation officers cannot be thermally upgraded using typical technologies that involve the external walls insulation retrofit by overcladding.

Old buildings, which are in various condition, were constructed using different technologies and materials used at the times a given structure was built. Every time the building envelope upgrading is planned, it is necessary to check the chemical composition, or conduct an analysis of the materials that will be used [12] with respect to the various material technologies applied [14] and its potential contribution to global warming [15]. The installation technology is also important, which was discussed, on the example of insulating lime-perlite render, in study [16]. Overall heat losses can be also reduced by means of wall orientation [17] as well as correct operation of ventilation and air conditioning, especially if passive systems are used [18].

Historical buildings can have different use: residential, religious, museums, theatres, libraries educational institutions and palaces [19]. For each type, it is necessary to select an appropriate heating scheme that would provide desirable indoor climatic conditions [20], and account for the thermal properties of the material used for thermal upgrading [21]. Heat pumps offer a good option as they rely on heat sources that are environmentally friendly because they reduce greenhouse gas emissions [22]. A heat pump should be selected depending on local climate, settings and building characteristics [23].

It poses a real challenge to find technical solutions that would ensure energy savings, and at the same time, allow the building users undertake a typical range of activities, the more so the other issue can only undergo qualitative assessment [24]. A wide selection of insulation materials is available on the market, however proper technologies are required to apply those materials. Therefore, while planning investment, a question must be answered what type of material should be used, and what costs that will generate. The outcome of selection, in other words, which solution will be implemented, depends on the energy source quality. The paper discusses simulation investigations into heat demand when the building is heated by an air-source heat pump.

\section{Climatic conditions}

All simulations of the supply of heat or cold to the buildings rely on the information on climatic conditions. For the sake of the design, rough estimations given in relevant standards, guidelines and recommendations are sufficient. As regards climatic conditions, in accordance with [25], five climatic zones are differentiated. In the zones, the design lowest winter external temperature ranges from $-16^{\circ} \mathrm{C}$ for the mildest zone located at the seaside, to $-24^{\circ} \mathrm{C}$ for the coldest mountainous areas. Similarly, annual average temperature for those two zones is $+7.7{ }^{\circ} \mathrm{C}$ and $5.5^{\circ} \mathrm{C}$, respectively. For the city of Kielce, the respective temperature values are -20 and
7.6. The calculations conducted in this way are useless while seeking optimal technical and economic solutions. That is a concern of particular importance when calculating the heating performance of the device that directly captures energy from the environment, the temperature of which depends, indirectly or directly, on ambient air. Heat pumps operate in this way. The ones for which the low temperature source are near-surface layers of the ground, and which harvest energy using a horizontal heat exchanger, depend on external conditions that vary over an approximately weekly cycle. As regards air-to-water heat pumps, their output directly depends on the momentary values of ambient air temperature. Then, if available, climatic data collected at the required frequency should be used.

In Poland, a high diversity in weather conditions is observed. The division into climatic zones acc. [26] does not account for local conditions, related, e.g. to the height of the location above sea level of a site. Simulation of the operation of the heat pump concerns a device operating in a building located in Kielce $\left(20^{\circ} 37^{\prime} \mathrm{E}\right.$ $50^{\circ} 53^{\prime} \mathrm{N}$ ), approx. $300 \mathrm{~m}$ asl. The distribution of mean temperatures for all the months of the year is shown in Fig. 1. Weather conditions undergo changes that are statistical in character. Figure 1 also identifies the ranges of temperature variation.

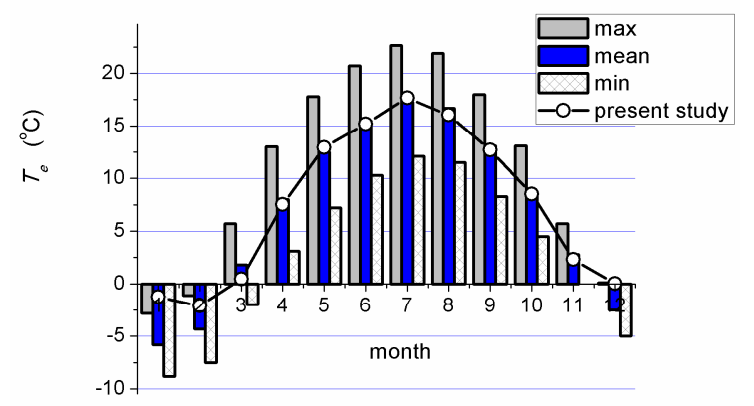

Fig. 1. Mean, minimal and maximal temperatures in Kielce in individual months of the year [26].

Meteorological data quoted in various sources depend on the site and time of measurement taking. In further computations, an hourly temperature distribution was adopted in accordance with [27]. The temperature data were obtained from the meteorological station in Suków, located closest to Kielce. The mean values were calculated for all the months. They do not differ much from the data shown in Fig. 1. Hourly counts of temperature with $1{ }^{\circ} \mathrm{C}$ increment are shown in Fig. 2. As can be seen, that really low temperatures hardly ever occur. The temperatures below $-10^{\circ} \mathrm{C}$ are recorded for approx. $3 \%$ of the heating season. Additionally, temperature measurements taken at high sampling frequency indicate that such cold conditions do not last all the day long. Temperature grows during daylight hours, consequently the demand for space heating of the building is correspondingly lower. The information of that kind should be taken into account while seeking the optimal heat pump for a given building. 


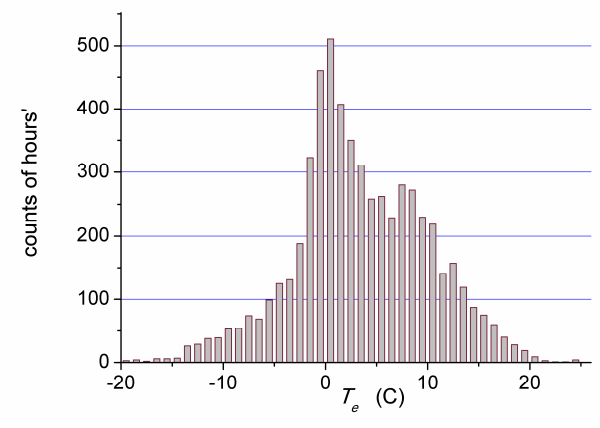

Fig. 2. Hourly counts of temperatures in Kielce [27].

\section{Heat pomp sizing and insulation material options}

Air-source heat pumps do not occupy much space, consequently they can be used in cities with dense built environment. Depending on power demand, a single- or multi-unit installations can be used. For moderate demand, single units are employed, which can be one- or two-compressor devices. The latter usually have higher output compared with the one-compressor pumps. The costs of purchase and later servicing of two-compressor heat pump is lower than the costs for two separate compressors. Exemplary characteristics of such a heat pump are shown in Fig. 3.

When trying to balance the thermal upgrading costs and benefits, the selection of materials options should be considered. That particularly refers to heritage buildings, in which all the works must be supervised by conservation officers. In a majority of cases, alterations to the building facades will not be approved. Then, the only option available, aimed at energy efficiency improvements and reduction in the heating costs, is to install insulation on the interior.

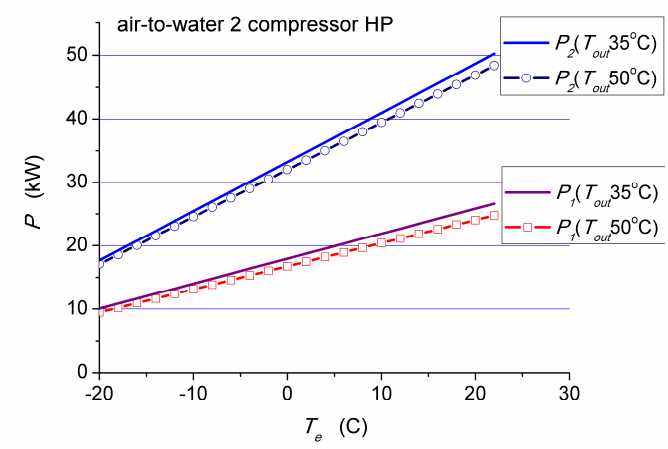

Fig. 3. Characteristic curves of two-compressor air-to-water heat pump.

The project must be preceded by moisture analysis of the envelope and space dividing elements, which should be carried out before and after insulation placement. That especially refers to materials such as Styrofoam or mineral wool. Thermally insulating plasters of various types, or cellular concrete blocks provide a safer solution in this respect. The thermal conductivity of a typical cement-lime plaster is approx. $0.82 \mathrm{~W} / \mathrm{mK}$. The need to thermally upgrade heritage buildings contributed to the production of plasters that have good insulation properties, and additionally, sufficient moisture permeability. Many products are available, the most popular ones are mortars using perlite as the main ingredient. The cheapest option is the preparation of the material on the site, the resulting product has the thermal conductivity coefficient that is a few times lower in comparison to the typical cement-lime plaster. Another option is the use of prefabricated lightweight cellular concrete blocks. The major drawback of this technology is a relatively large minimal thickness of the insulation. Additionally, it is also necessary to apply a finishing coat. As a result, the project costs increase. Another option is rigid polyurethane foam that is finished on one side with gypsum wallboard. That, however, is the most expensive technology, therefore less frequently used.

Other insulation materials to be installed on the building interior surface are also available on the market. The choice results from technical and economic analysis that needs to be carried out on individual basis, or from the investor's preferences. In this paper, the analysis aimed at finding the optimal solution was carried out using the example of a thermally insulating plaster based on perlite. It was assumed that the building envelope, 0.4 $\mathrm{m}$ in total thickness, was made of brick and the envelope thermal resistance is $0.506 \mathrm{~m}^{2} \mathrm{~K} / \mathrm{W}$. The overall heat load was assumed to be equal to $36 \mathrm{~kW}$ (including $3 \mathrm{~kW}$ for domestic hot water generation). As a result of the modernisation of the heating system, the load requirement is to be satisfied by the air-source heat pump, the characteristics of which are presented in Fig. 3. It is a two-compressor device, with the first compressor operating at moderate external temperatures, while the second one starts functioning when the temperatures drop. Thermal power demand is illustrated, in a simplified manner, in Fig. 4.

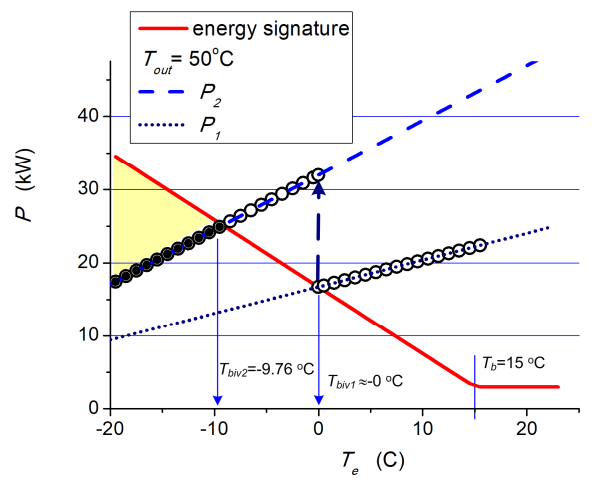

Fig. 4. Heat pump contribution to the building energy signature.

It was assumed that the object space heating starts when the external temperature drops below the base temperature $T_{b}=15^{\circ} \mathrm{C}$. The heating curve intersects the pump characteristics curve at two points. The first point specifies the maximum power that can be utilised when the heat pump operates using one compressor. At the external temperature lower than $T_{b i v l}$, the pump starts the operation mode with two compressors activated. It is 
possible to fully meet power demand only until the ambient air temperature is above the bivalence point, i.e. $T_{e}>T_{\text {biv2 }}$. Then, the heat pump must be supplemented by an additional heat source, e.g. a boiler. In the paper, a monovalent mode with a backup electric heater was assumed. For a vast range of external temperatures, the heat pump operates generating surplus-to-demand power. That makes it necessary to frequently switch the pump on and off, which results in decreasing the actual value of the coefficient of performance. The manufactures of heat pumps do not always specify this value. Coefficient of performance of heat pump under partial load conditions $C O P_{\text {bin }}$ at temperature $T_{\mathrm{j}}$ may be calculated in accordance with [28]:

$$
\operatorname{COP}_{\text {bin }}\left(T_{j}\right)=C O P \frac{P_{h}}{C c P_{h}+(1-C c) P_{d}}
$$

where: $P_{\mathrm{h}}=P_{h}\left(T_{j}\right)$ - heat load of the building at temperature $T_{\mathrm{j}}, P_{\mathrm{d}}=P_{\mathrm{d}}\left(T_{j}\right)$ - power output of the heat pump at temperature $T_{\mathrm{j}}$,

$C c$ (i) in Eq. (1) is the heat pump capacity ratio, namely the ratio between the thermal power delivered by the heat pump and the maximum power which the heat pump could deliver at the $i$ th bin conditions.

The values of this coefficient for the individual ranges of the heat pump operation are shown in Fig. 5.

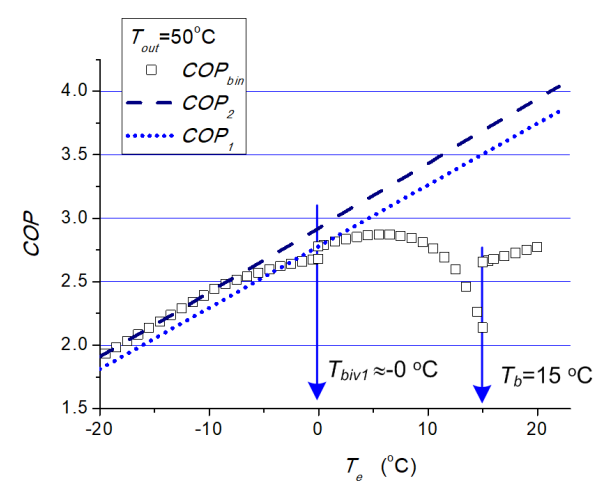

Fig. 5. Coefficient of performance of heat pump under partial load conditions $\mathrm{COP}_{\text {bin }}$ and full load for one- and twocompressor mode of operation.

\section{Optimal insulation thickness}

When seeking optimal solutions for a thermal upgrading project, it is necessary to balance overall costs $C_{A, N}$ that include space heating costs, insulation placement costs and the costs of necessary materials. The following notation can be used: $f_{l}$ and $f_{2}=1-f_{l}$ represent the share of the building opaque part and the part of it (e.g. windows) that is not thermally upgraded, respectively, $U_{1}$ and $U_{2}$ denote respective overall heat transfer coefficients, $R_{\mathrm{w}}$ stands for thermal resistances of subsequent layers of the envelope element, $d_{\text {ins }}$ and $\lambda_{\text {ins }}$ refer to thickness and thermal conductivity of the insulation material. The total costs $C_{A, N}$ in reference to $1 \mathrm{~m}^{2}$ can be calculated from the following formula [29]:

$$
\begin{aligned}
& C_{A, N}=\left(\frac{f_{1}}{R_{w}+d_{\text {ins }} / \lambda_{\text {ins }}}+U_{2} f_{2}\right) N C_{E m} * \\
& * \sum_{j}\left(T_{i}-T_{j}\right) \frac{\tau_{j}}{C O P_{b i n}\left(T_{j}\right)}+N C_{N p}\left(d_{\text {ins }} C_{i n s}+C_{d}\right)
\end{aligned}
$$

If the thermo-modernisation investment is carried out with the funds obtained through the bank loan at fixed interest rate $i_{r}$ at all $N$ years, coefficient describing the cost of credit $C_{N p}$ is:

$$
C_{N p}=i_{r} \frac{\left(1+\frac{i_{r}}{12}\right)^{12 N}}{\left(1+\frac{i_{r}}{12}\right)^{12 N}-1}
$$

Figure 6 shows a change in heating costs, insulation costs and overall costs depending on the insulation thickness.

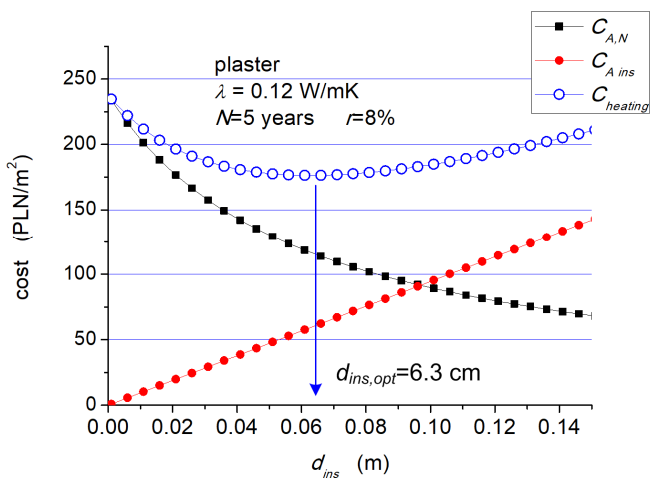

Fig. 6. Costs of plaster insulation for five-year term of loan and at $8 \%$ fixed interest rate.

The computations were made for thermally insulating mortar with thermal conductivity of $\lambda=0.12 \mathrm{~W} / \mathrm{mK}$, as declared by the manufacturer. Plaster is applied in coats of up to $3 \mathrm{~cm}$ in thickness. For multi-coat insulation, the placement costs increase proportionally. A fixed interest rate $i_{r}=8 \%$ and 5 -year loan repayment term were assumed. Ambient air is a low temperature heat source for the compressor heat pump. The hourly distribution of mean thermal conditions of the ambient air is shown in Fig. 2. In the case under consideration, the optimum insulation thickness is $d_{\text {ins_opt }}=6.3 \mathrm{~cm}$, and the insulation should be placed in two approx. $3 \mathrm{~cm}$ thick coats.

The investor's decision is to choose the loan period for the investment, which - as shown in Fig. 7 - affects the optimal insulation thickness. Along with the extension of the repayment period, the initial costs also increase. It also causes a corresponding change in the energy demand. For data from Fig. 7, energy consumption compared to the state before thermomodernization decreases by approximately $38 \%, 51 \%$ and $58 \%$ at respectively 3,5 and 7 years of loan repayment terms. 


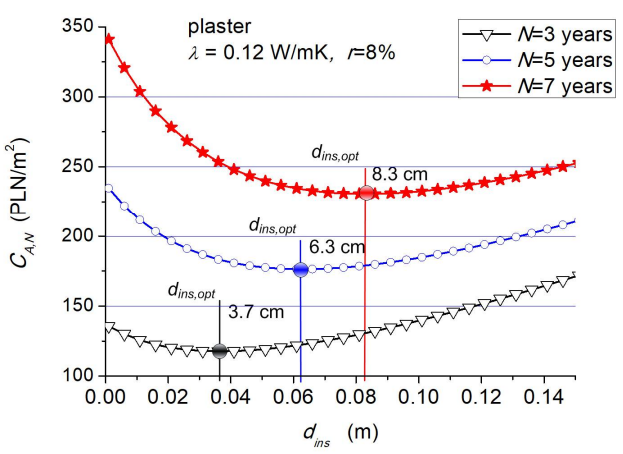

Fig. 7. Change of the optimal insulation thickness at different terms of loan with a fixed interest rate.

\section{Conclusions}

From equation 2, the insulation optimal thickness can be calculated. The value is equal to approx. $6.3 \mathrm{~cm}$. The optimal thickness is the one for which the overall costs will be minimal [21]. In the case presented in Fig 6, a relatively low increase in costs can be seen in the proximity of $d_{\text {ins opt }}$. In the plaster thickness range from $1.7 \mathrm{~cm}$ to $10 \mathrm{~cm}$, the increase is not higher than $5 \%$, which produces a rational change in the thermal performance of the envelope elements (walls). On the basis of such information, the investor can make a decision on increasing the thickness of the plaster applied, unless limits are put on, e.g. floor area reduction.

In addition to the costs of space heating and insulation materials, the costs of the heating device replacement must also be taken into account in the thermal upgrading project. The price of the heating pumps available on the market is related to their output. The heat pump under consideration in this study has the output of $32 \mathrm{~kW}$ when it is supplied with air at the temperature of $T_{e}=0^{\circ} \mathrm{C}$, and the bivalence point is $T_{b i v}=9.2^{\circ} \mathrm{C}$. After thermo-modernization, the heating power needed drops. For the building of concern, it is possible to select a one-compressor heat pump having such characteristics so that the bivalence point would remain unchanged. The required output should be about $20 \mathrm{~kW}$ at the temperature of $T_{e}=0^{\circ} \mathrm{C}$, the purchase price will be about $30 \%$ lower. Assuming a fixed interest rate of $8 \%$, net present value (NPV) can be calculated. It has a positive value after 18 years or 12 years, for two- and one-compressor heat pump, respectively. That indicates when designing thermal modernisation of buildings with thermal upgrading chosen on individual basis, it is also necessary to account for the ultimate parameters of the heating device.

\section{References}

1. D. Król, S. Poskrobko, Energy \& Fuels, 31(4) (2017)

2. D. Król, S. Poskrobko, Energy, 116 (2016)

3. T. Orzechowski, M. Orzechowski, E3S Web Conferences, 14 (2017)
4. M. Ali, V. Vukovic, N.A. Sheikh, H.M. Ali, Energy Energy Convers. Manage. 97 (2015)

5. http://hpc2017.org/wp-content/uploads /2017/06/k211.pdf. (Last accessed Feb. 2018)

6. V. Bianco, F. Scarpa, L.A. Tagliafico, Appl. Therm. Eng. 114 (2017)

7. W. Wu, W. Shi, B. Wang, L Xianting, Energy Convers. Manage. 98 (2015)

8. W. Deng, J. Yu, Energy Convers. Manage. 120 (2016)

9. Y. Zhang, Q. Ma, B. Li, X. Fan, Z. Fu, Energy Build. 138 (2017)

10. M. Dongellini, C. Naldi, G.L. Morini, Appl. Therm. Eng. 114 (2017)

11. M. Maivel, J. Kurnitski, Energy Build. 94 (2015)

12. L. Yang, H. Yuan, J-W. Peng, C-L. Zhang, Renewable Energy, 87 (2016)

13. Z. Owsiak, J. Zapała-Sławeta, P. Czapik. Bull. PAS: Tech. Sci. 63(1) (2015)

14. R. Dachowski, P. Kostrzewa, E3S Web Conferences, 10 (2017)

15. C. Hill, A. Norton, J. Dibdiakova, Energy Build. 162 (2018)

16. Y. Govaerts, R. Hayen, M. Bouw, A. Verdonck, W. Meulebroeck, S. Mertens, Y. Grégoire, Constr. Build. Mater. 159 (2018)

17. I. Csáky, F. Kalmár, J. Build. Phys. 39(2) (2015)

18. A. Rackes, A.P. Melo, R. Lamberts, Appl. Energy, 174 (2016)

19. A. Martínez-Molina, I. Tort-Ausina, S. Cho, J-L. Vivancos, Renew. Sust. Energ. Rev. 61 (2016)

20. S. Bichlmair, S. Raffler, S. Kilian, Energy Build. 95 (2015)

21. R. Walker. S. Pavía, Build. Environ. 94 (2015)

22. R. Dylewski, J. Adamczyk, Build. Environ. 46 (2011)

23. C. Naldia, G.L. Morinia, E. Zanchini, Sust. Cities Soc. 12 (2014)

24. K. Fabbri, J. Cult. Heritage, 14S (2013)

25. Polish standard PN-EN 12831 (2006)

26. Local Data Bank Warsaw: www.stat.gov.pl. (Last accessed October 2017)

27. www.mib.gov.pl. (Last accessed Oct. 2017)

28. Standard EN 14825 (2013)

29. T. Orzechowski, M. Orzechowski, J. Build. Phys. 1 (2017) 